\title{
Enlarged adrenal glands: the long-term consequence of Cushing's disease
}

\author{
Yorihiro Iwasaki $^{1}$ - Akihiro Hamasaki ${ }^{1}$
}

Received: 9 November 2018 / Accepted: 9 January 2019 / Published online: 4 February 2019

(c) The Author(s) 2019

Case report;

A 51-year-old woman presented with progressive swelling of the face with lower extremity edema. At age 38, she was initially diagnosed as having Cushing's disease caused by a pituitary corticotroph adenoma (Fig. 1a). At that time, bilateral adrenal glands were not enlarged (Fig. 1b). Initially, she underwent transsphenoidal surgery. Pathological diagnosis was sparsely granulated corticotroph adenoma with positive immunostaining for adrenocorticotropic hormone (ACTH). Ki-67-positive cells were less than $1 \%$. Postoperatively, however, residual tumor remained in the cavernous sinus. Postoperative pituitary irradiation was ineffective to control ACTH. Octreotide and cabergoline were also ineffective, and pasireotide had not been approved for Cushing's disease in Japan. Her plasma ACTH remained high, around $100 \mathrm{pg} / \mathrm{ml}$ (normal range $7.2-63.3 \mathrm{pg} / \mathrm{ml}$ ), and thereafter, her hypercortisolemia had been medically managed with metyrapone, a steroidogenesis inhibitor, over 10 years (Fig. 1a). She could not tolerate mitotane, an adrenolytic agent, because of the adverse effect of gastrointestinal disturbances. At age 51, bilateral adrenal glands became greatly enlarged (Fig. 1c), and hypercortisolemia became uncontrollable with high-dose metyrapone (4000-6250 mg/day, Fig. 1a). Consequently, systemic edema, hyperglycemia, hypertension, and hypokalemia worsened progressively. Therefore, she underwent laparoscopic bilateral adrenalectomy (Fig. 1d). Pathologically, enlarged bilateral adrenal glands were composed of zona fasciculata-like cells with no evidence of mitotic figures, necrosis, or vascular invasions. Following adrenalectomy, she was on hydrocortisone replacement therapy. Twelve

Akihiro Hamasaki

a-hamasaki@kitano-hp.or.jp

1 Center for Diabetes and Endocrinology, Tazuke Kofukai Medical Research Institute Kitano Hospital, 2-4-20 Ohgimachi, Kitaku Osaka 530-8480, Japan months after adrenalectomy, she remains well, and there is no sign of remaining pituitary tumor growth on magnetic resonance imaging (Fig. 1a).

In patients with Cushing's disease who are refractory to initial treatments for pituitary tumor, hypercortisolemia must be managed medically or surgically [1]. Although bilateral adrenalectomy is the most reliable option for the treatment of hypercortisolemia, it may be associated with potential risk of pituitary tumor growth, known as Nelson's syndrome [2]. Therefore, physicians are often reluctant to decide adrenalectomy [3]. On the other hand, the "escape" phenomenon from response has been reported in the longterm treatment with steroidogenesis inhibitors [1]. Although the underlying mechanism of the phenomenon remains unclear, as for metyrapone, long-term treatment may result in "escape" in 4-13\% of patients (Table 1) [4-6]. A plausible explanation of "escape" in the current case would be that long-term stimulation by ACTH lead to marked enlargement of adrenal glands with robust production of cortisol, which could not be suppressed by high-dose metyrapone. Another possibility is that enlarged adrenal glands autonomously secreted cortisol, as suggested by previous reports $[1,7,8]$. However, because of persistently elevated plasma ACTH in the current case, it is difficult to determine whether cortisol was autonomously produced independently of ACTH.

In conclusion, the current case highlights the difficulty in long-term treatment of Cushing's disease, especially with metyrapone. The optimal timing for bilateral adrenalectomy is not clearly defined, and physicians must make difficult decisions in the management of refractory Cushing's disease. 

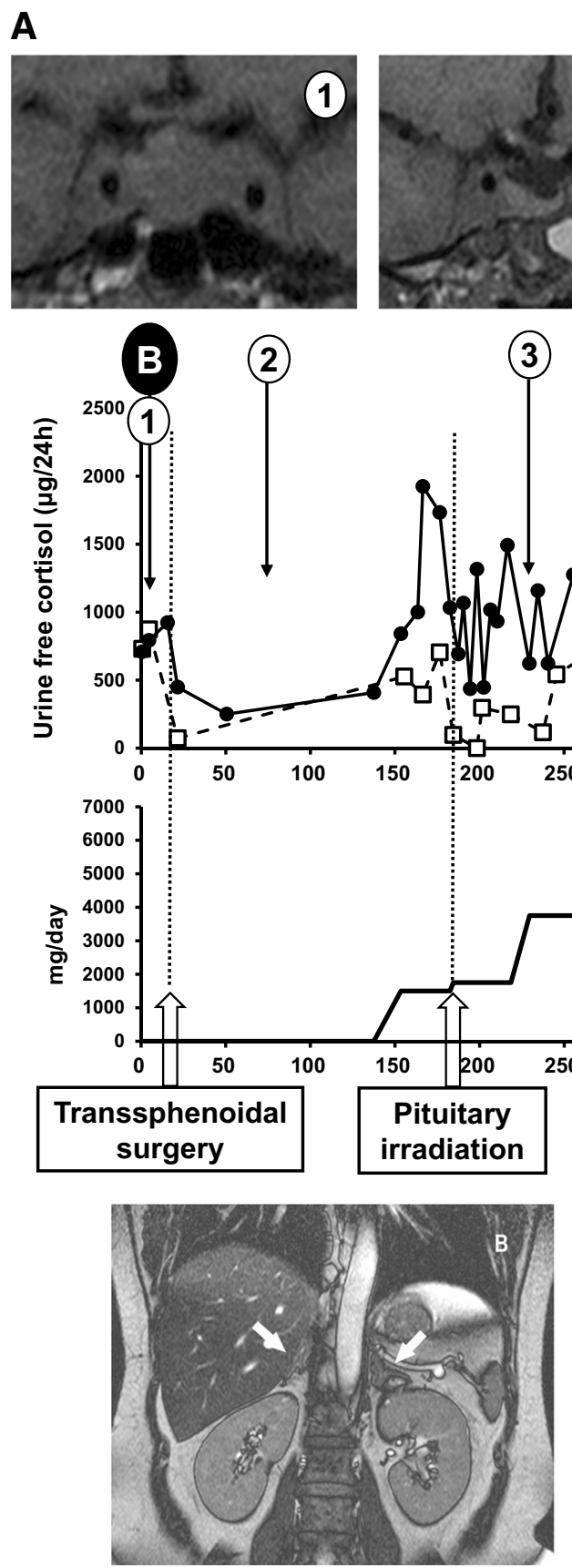

Fig. 1 a The time course of treatment. Horizontal axes of the upper and lower graphs show weeks from the time of diagnosis. In the upper graph, changes in urine free cortisol in $24 \mathrm{~h}$ urine specimens (dashed line) and plasma ACTH (solid line) are shown. In the lower graph, changes in metyrapone dose are shown. At the bottom, the timings of transsphenoidal surgery, pituitary irradiation, and bilateral adrenalectomy are shown with arrows and dashed lines. Four pituitary T1weighted coronal MRI images on the top were taken at the indicated
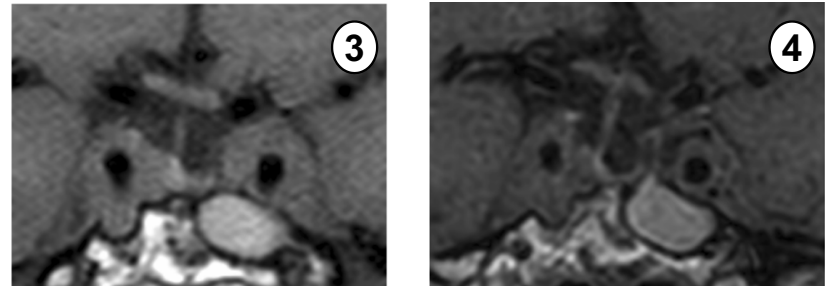

(4)

$-\square$-Urine free cortisol $(\mu \mathrm{g} / 24 \mathrm{~h})$

$\rightarrow$-ACTH $(\mathrm{pg} / \mathrm{ml})$

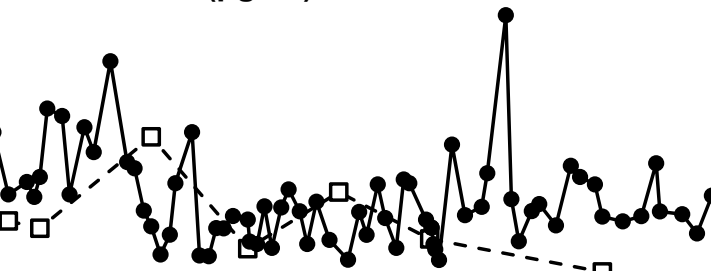

C (4)

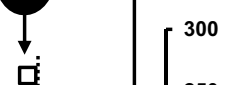

250 200 产

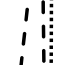
$\int_{0}^{100}$

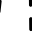
1: 700 (weeks)

Metyrapone (mg/day)

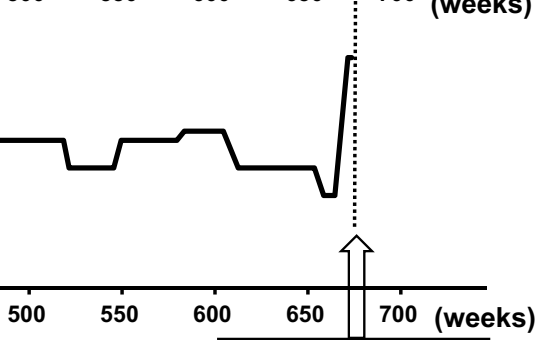

Bilateral adrenalectomy
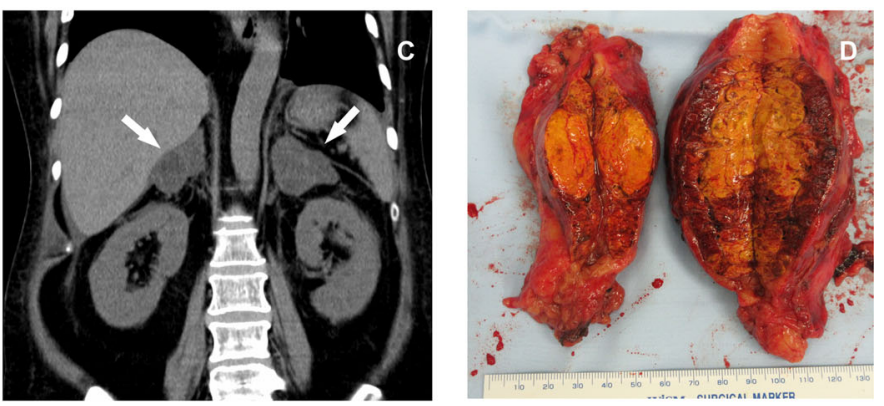

time points (marked as "1"-“4"). Black-circled "B" and "C" are the time points when $\mathbf{b}$ and $\mathbf{c}$ imaging studies were performed, respectively. b Abdominal MRI of bilateral adrenal glands (arrows) at the time of diagnosis of Cushing's disease. c Abdominal CT showing enlarged bilateral adrenal glands (arrows) 13 years after diagnosis of Cushing's disease. d Surgically resected right (left on the photograph) and left (right on the photograph) adrenal glands 
Table 1 Review of the literature of the "escape" phenomenon in long-term metyrapone-treated patients with Cushing's syndrome

\begin{tabular}{llllll}
\hline Authors & Number of cases & Number of "escape" & Duration of treatment & Morphological changes in adrenal glands & Reference \\
\hline Verhelst et al. & 24 & 1 & $3-140$ months & Not characterized. & Not characterized. \\
Valassi et al. & 23 & 3 & $1-30.7$ months & Not characterized. & {$[4]$} \\
Ceccato et al. & 31 & 3 & $3-12$ months (interquartile range) & {$[5]$} \\
\hline
\end{tabular}

\section{Compliance with ethical standards}

Conflict of interest The authors declare that they have no conflict of interest.

Ethical approval This article does not contain any studies with human participants or animals performed by any of the authors.

Informed consent Informed consent was obtained from all individual participants included in the study.

Publisher's note: Springer Nature remains neutral with regard to jurisdictional claims in published maps and institutional affiliations.

Open Access This article is distributed under the terms of the Creative Commons Attribution 4.0 International License (http://crea tivecommons.org/licenses/by/4.0/), which permits use, duplication, adaptation, distribution, and reproduction in any medium or format, as long as you give appropriate credit to the original author(s) and the source, provide a link to the Creative Commons license, and indicate if changes were made.

\section{References}

1. R. Pivonello, M. De Leo, A. Cozzolino, A. Colao, The treatment of Cushing's disease. Endocr. Rev. 36, 385-486 (2015)
2. D.H. Nelson, J.W. Meakin, J.B. Dealy Jr, D.D. Matson, K Emerson Jr, G.W. Thorn, ACTH-producing tumor of the pituitary gland. N. Engl. J. Med. 259, 161-164 (1958)

3. L.F. Morris, R.S. Harris, D.R. Milton, S.G. Waguespack, M.A. Habra, C. Jimenez, R. Vassilopoulou-Sellin, J.E. Lee, N.D. Perrier, E.G. Grubbs, Impact and timing of bilateral adrenalectomy for refractory adrenocorticotropic hormone-dependent Cushing's syndrome. Surgery 154, 1174-1184 (2013)

4. J.A. Verhelst, P.J. Trainer, T.A. Howlett, L. Perry, L.H. Rees, A. B. Grossman, J.A. Wass, G.M. Besser, Short and long-term responses to metyrapone in the medical management of 91 patients with Cushing's syndrome. Clin. Endocrinol. (Oxf.). 35, 169-178 (1991)

5. E. Valassi, I. Crespo, I. Gich, J. Rodríguez, S.M. Webb, A reappraisal of the medical therapy with steroidogenesis inhibitors in Cushing's syndrome. Clin. Endocrinol. (Oxf.). 77, 735-742 (2012)

6. F. Ceccato, M. Zilio, M. Barbot, N. Albiger, G. Antonelli, M. Plebani, S. Watutantrige-Fernando, C. Sabbadin, M. Boscaro, C. Scaroni, Metyrapone treatment in Cushing's syndrome: a real-life study. Endocrine 62, 701-711 (2018)

7. A.M. Pereira, M.O. van Aken, H. van Dulken, P.J. Schutte, N.R. Biermasz, J.W. Smit, F. Roelfsema, J.A. Romijn, Long-term predictive value of postsurgical cortisol concentrations for cure and risk of recurrence in Cushing's disease. J. Clin. Endocrinol. Metab. 88, 5858-5864 (2003)

8. E. Valassi, B.M. Biller, B. Swearingen, F. Pecori Giraldi, M. Losa, P. Mortini, D. Hayden, F. Cavagnini, A. Klibanski, Delayed remission after transsphenoidal surgery in patients with Cushing's disease. J. Clin. Endocrinol. Metab. 95, 601-610 (2010) 